\title{
Influence of Maximum Particle Diameter on the Mechanical Behavior of Soil-Rock Mixtures
}

\author{
Zhuoling He $\mathbb{D}^{1},{ }^{1}$ Junyun Zhang $\mathbb{D}^{1},{ }^{1}$ and Tao Sun $\mathbb{D}^{2}$ \\ ${ }^{1}$ School of Civil Engineering, Southwest Jiaotong University, Chengdu 610031, China \\ ${ }^{2}$ China Tiesiju Civil Engineering Group Co. Ltd., Hefei 610031, China \\ Correspondence should be addressed to Junyun Zhang; zjywxfbb@swjtu.edu.cn
}

Received 27 July 2020; Revised 24 August 2020; Accepted 28 August 2020; Published 14 September 2020

Academic Editor: Xuzhen He

Copyright (c) 2020 Zhuoling He et al. This is an open access article distributed under the Creative Commons Attribution License, which permits unrestricted use, distribution, and reproduction in any medium, provided the original work is properly cited.

With the steady development of the development of the western region in China, the construction of mountain highways has developed rapidly, and the soil-rock mixed filler, as an excellent filler, is widely used in the subgrade filling of mountain highways. Unlike ordinary fine-grained soil, the source of the soil-rock mixtures (S-RMs) is not unique, and the particle size difference is large and the water content is not uniform, resulting in very complicated mechanical properties. But the current highway embankment codes are still mainly established on the fine-grained soil. It is not fully applicable to soil-rock filled embankment. Based on soil-rock filled embankment engineering practice, this research uses a large-scale direct shear test to research the mechanical characteristics of the S-RMs with different maximum particle diameters. According to the large-scale direct shear test of S-RMs with different maximum particle diameters, the shear displacement vs shear stress curve, shear dilation, and strength characteristics with maximum particle diameter were analyzed. Results demonstrate that whether secondary hardening occurs mainly depends on the normal stress and the maximum particle diameter of the filler. At different maximum particle diameters, the horizontal displacement vs vertical displacement curves of the S-RMs can be roughly divided into continuous shearing and beginning of shearing and quick dilation. And the shear strength increases with the increase of the maximum particle diameter. Moreover, the cohesion decreases first and then increases with the increase of the maximum particle diameter, and the internal friction angle increases with the increase of the maximum particle diameter. Therefore, some RBs with large particle diameter added to filler can effectively improve the shear strength of the S-RMs, which may be valuable for realistic engineering.

\section{Introduction}

Soil-rock mixtures (S-RMs) are typical anisotropy geomaterials, widely existing in many construction projects, such as tunnels, dams, and slopes [1]. The complex shear behavior of the S-RMs has attracted the attention of many researchers for a long time.

Current research is mainly focused on the influence of rock blocks (RBs) particle size distribution and content on the shear strength of S-RMs. Many research studies indicate that the spatial arrangement and size distribution of the internal RBs have a favorable feature of regularity in the sense of statistics [2-9]. Several scholars have studied the effect of rock block proportion (RBP) on the S-RMs shear strength. These studies demonstrate that the increment of
RBP has different influences on strength at different stages, there are obvious RBP thresholds in strength variations, and RBs can provide friction and strength for the S-RMs [10-12].

In the previous studies, Wang et al. [13] investigated the granulometric characteristics, surface characteristics, and directional and shape characteristics of RBs in S-RMs by digital image processing technique. Casagli et al. [14] studied the grain size distribution of S-RMs by volumetric sieve analysis and grid by number analysis. Sass and Krautblatter [15] applied the ground-penetrating radar to gain insight into the internal sediment structures. Within the past decades, laboratory tests, such as triaxial tests, consolidation tests, and direct shear tests, have been conducted to study the influence of the RBP and grain size distribution on the shear behavior of S-RMs. The large-scale direct shear tests on the 
strength of the S-RMs under different RBP are recognized [16-19]. In this paper, the large-scale direct shear test is used to study the influence of the maximum particle diameter on the shear displacement vs shear stress curve characteristics, shear dilation, or shear shrinkage characteristics and the influence of shear strength characteristics on shear strength parameters.

\section{Materials and Methods}

2.1. Large-Scale Direct Shear Test. The direct shear test has been proved to be efficient in measuring the shear strength parameters of geotechnical materials. In this research, ZY50$5 \mathrm{C}$ was used for the large-scale direct shear test. ZY50-5C is mainly composed of the control system and host structure, acquisition system, and hydraulic system, as shown in Figure 1. The hydraulic system is mainly composed of highpressure oil pump, oil filter, high-precision microflow speed control valve, high-pressure gas cylinder, gas-liquid hydraulic balance valve, hydraulic switch, etc. The host structure is mainly composed of vertical jacks, horizontal jacks, vertical load sensors, horizontal load sensors, vertical displacement sensors, horizontal displacement sensors, upper and lower shear boxes, and cantilever cranes.

The upper and the lower shear boxes have the same scale, $\Phi 504 \mathrm{~mm} \times 400 \mathrm{~mm}$. Furthermore, during the sample preparation, a shear joint of $10 \mathrm{~mm}$ spacing is reserved between the two shear boxes. The vertical maximum loading for $700 \mathrm{kN}$ with a $50 \mathrm{~mm}$ vertical sensor. The maximum horizontal loading force and displacement are $700 \mathrm{kN}$ and $70 \mathrm{~mm}$, respectively.

The vertical jack is installed under the top beam, and the horizontal jack is installed on the right side of the horizontal reaction seat on the right side of the host structure to form the reaction point with the horizontal reaction seat. There is a rolling shaft row under the lower shear box, to push the shear box to move forward and backward and to facilitate the loading and unloading of the sample. The cantilever crane is welded on the top beam, with a range of $10 t$, for lifting the shear box after loading. Slotted balls are installed on the side of the lower shear box and the lower part of the upper shear box to control the slit height during shearing.

The vertical load sensor is installed in the vertical jack, and the horizontal load sensor is installed in the horizontal jack to collect the load in the vertical and horizontal directions, respectively. Four high-precision grating vertical displacement sensors are evenly distributed on the upper shear box along the circumference. And a high-precision horizontal displacement sensor is installed on the right side of the bottom of the shear box. During the test, the loading and unloading are carried out through the control cabinet. The load and displacement data during the test are collected with sensors and displayed on the computer. Then, the collected data can be exported from the computer for analysis.

The speed adjustment is controlled by a high-precision microflow speed control valve. Manually adjusting the knob of the microflow speed control valve in clockwise direction will increase the shear speed. And the shear speed will be reduced when it goes in anticlockwise direction. When the speed is adjusted properly, the oil cylinder will move at the current adjusted speed.

High-pressure oil pump, oil filter, high-pressure cylinder, gas-liquid hydraulic balance valve, and hydraulic switch are used to load the sample. The hydraulic system is controlled manually, and the motor drives the oil pump to produce high-pressure hydraulic pressure. The balance valve is controlled by high-pressure nitrogen, and the hydraulic pressure is driven through the high-pressure steel pipe to drive the hydraulic jack, thus exerting vertical or horizontal load. After the vertical load is applied, the upper shear box is kept still. Under the transverse load, the lower shear box moves backward. Because the horizontal load is strain controlled, data can be collected by equal displacement.

2.2. Sample Preparation. Considering that the source of the $\mathrm{S}$-RMs filler in the realistic engineering is not unique, the soil in the S-RMs chooses quartz sand and the rock chooses the mixture of sand pebbles and relatively low-strength concrete blocks, as shown in Figure 2. The dry density of the samples was maintained at $2.0 \mathrm{~g} \cdot \mathrm{cm}^{-3}$ with the RBP of $40 \%$.

Lindquist and Goodman $[20,21]$ carried a detailed research and gave the soil-rock threshold for judging "soil" and "rock" fractions of S-RMs as follows:

$$
\begin{aligned}
f & = \begin{cases}R, & \left(d \geq d_{\mathrm{thr}}\right), \\
S, & \left(d<d_{\mathrm{thr}}\right),\end{cases} \\
d_{\mathrm{thr}} & =0.05 L_{c},
\end{aligned}
$$

where $S$ and $R$ represent "soil" and "rock" in S-RMs; $d_{\text {thr }}$ is the soil-rock threshold; and $L_{c}$ is the characteristic engineering scale of the S-RMs.

According to the direct shear test size used in this paper, the characteristic engineering scale $\left(L_{c}\right)$ is equal to the shear box's height, and based on equation (2), the value of soilrock threshold $\left(d_{\mathrm{thr}}\right)$ should be equal to $0.05 \times 400=20 \mathrm{~mm}$. This test uses $20 \mathrm{~mm}$ as the soil-rock threshold.

The maximum particle diameters of the S-RMs are divided into three grades of $40 \mathrm{~mm}, 60 \mathrm{~mm}$, and $80 \mathrm{~mm}$, and the proportion of the fine particles below $20 \mathrm{~mm}$ is kept the same. A group of reshaped soil samples with a maximum particle diameter of $20 \mathrm{~mm}$ are also prepared as a contrast test. Then, large-scale direct shear tests under four different normal stresses are carried out, a total of 16 sets of tests, to explore the effect of the maximum particle diameter on the mechanical properties of the S-RMs. The particle composition of the S-RMs is shown in Table 1 and Figure 3.

\subsection{Experimental Procedure}

2.3.1. Sample Preparation. Consider that in realistic engineering, each layer compaction quality of S-RMs filler is ensured by the compaction machinery and the compaction passes. This research refers to the method of controlling compaction energy is used for sample preparation. 


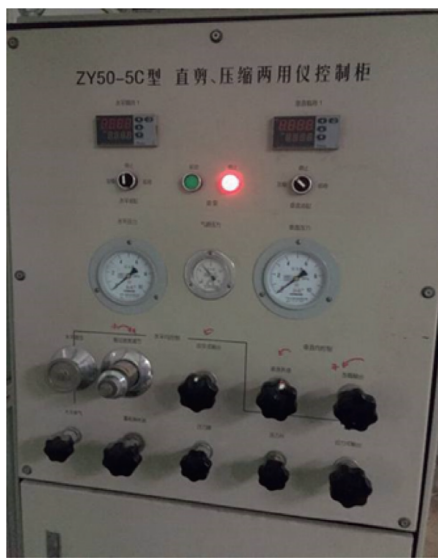

(a)

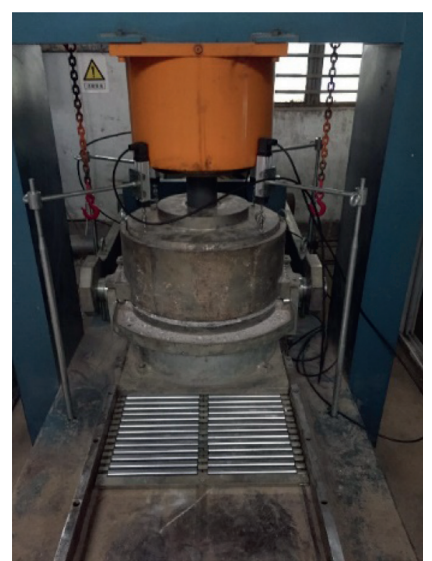

(b)

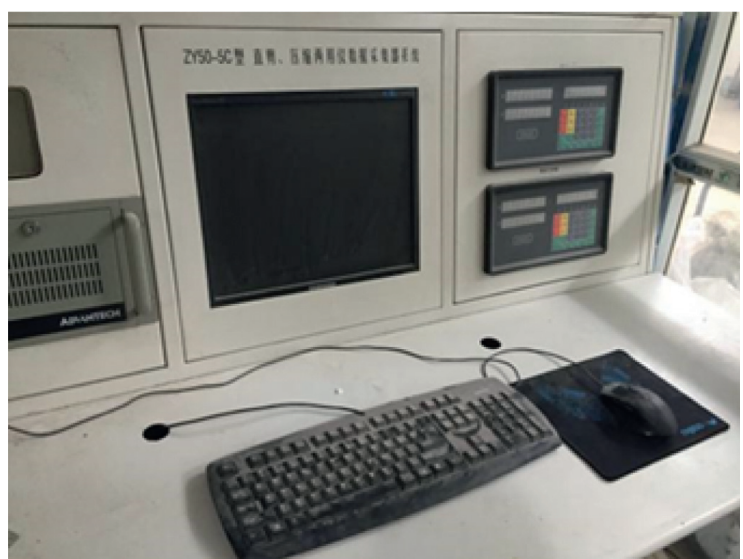

(c)

Figure 1: ZY50-5C. (a) Control system. (b) Host structure. (c) Acquisition system.

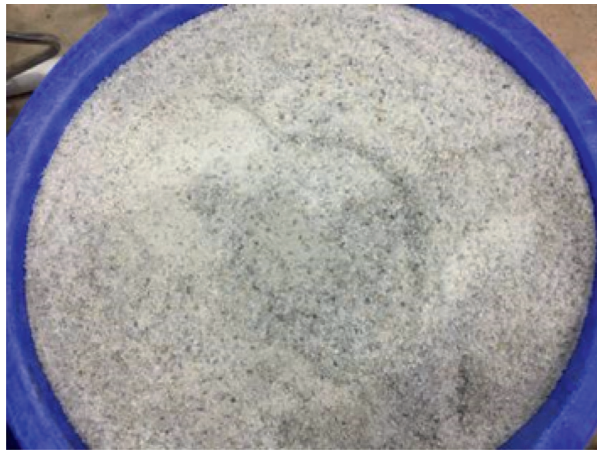

(a)

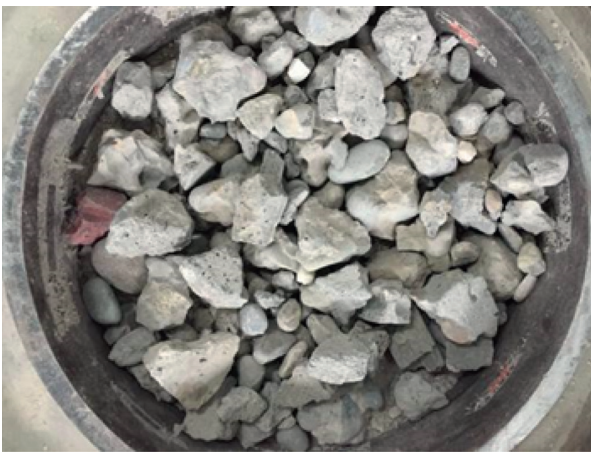

(b)

Figure 2: S-RMs filler. (a) Quartz sand. (b) Mixture of sand pebbles and concrete blocks.

TABLE 1: Grading of S-RMs specimens (unit: \%).

\begin{tabular}{lccccc}
\hline \multirow{2}{*}{ Particle diameter $d(\mathrm{~mm})$} & & \multicolumn{4}{c}{$\begin{array}{c}\text { Maximum particle diameter } \\
(\mathrm{mm})\end{array}$} \\
\hline \multirow{3}{*}{ Coarse particle } & $60 \sim 80$ & - & - & - & 20.0 \\
& $40 \sim 60$ & - & - & 20.0 & 10.0 \\
& $20 \sim 40$ & - & 40.0 & 20.0 & 10.0 \\
\hline \multirow{3}{*}{ Fine-grained particle } & $10 \sim 20$ & 40.0 & 24.0 & 24.0 & 24.0 \\
& $5 \sim 10$ & 10.0 & 6.0 & 6.0 & 6.0 \\
& $2 \sim 5$ & 20.0 & 12.0 & 12.0 & 12.0 \\
& $1 \sim 2$ & 15.0 & 9.0 & 9.0 & 9.0 \\
& $0.5 \sim 1$ & 6.0 & 3.6 & 3.6 & 3.6 \\
& $0.25 \sim 0.5$ & 4.0 & 2.4 & 2.4 & 2.4 \\
& $<0.25$ & 5.0 & 3.0 & 3.0 & 3.0 \\
\hline
\end{tabular}

The tested sample was compacted layer by layer in three layers in the shear box. Each layer was compacted slightly to the targeted height using a rubber hammer. The prepared specimen had a density of about $2 \mathrm{~g} \cdot \mathrm{cm}^{-3}$. Each layer of the sample was scarified on the surface before filling the next layer to minimize the heterogeneity induced by the compaction. After compaction, the top of the sample was filled with a thin layer of fine soil to help the applied load be uniformly distributed on the upper surface.
2.3.2. Shearing. The shearing of the sample can be roughly divided into five steps: shear box position fixing, vertical precontact, horizontal precontact, vertical loading, and horizontal shearing.

(1) Shear Box Position Fixing. The shear box on the roller row with a lifting cantilever is lifted, and the shear box is pushed onto the axis position along the roller row track in a line with the axis of the axial jack. The two tension rods connected with the horizontal reaction beam are lowered, and the lower shear box with the horizontal reaction beam is connected to form a reaction system. The above ensures that the upper shear box is still and the lower shear box moves horizontally backwards during the shearing process. Then, the slit ring and the retaining pin are taken out, and four vertical displacement sensors and one horizontal displacement sensor are installed.

(2) Vertical Precontact. The high-pressure nitrogen cylinder switch is opened, and the vertical cylinder is hit to the loading position. Then, the stress output and vertical oil supply knob are opened in the control system, and the oil pump is opened. Until the pointer on the vertical pressure gauge is between 1 and $2 \mathrm{MPa}$, the vertical oil supply knob 


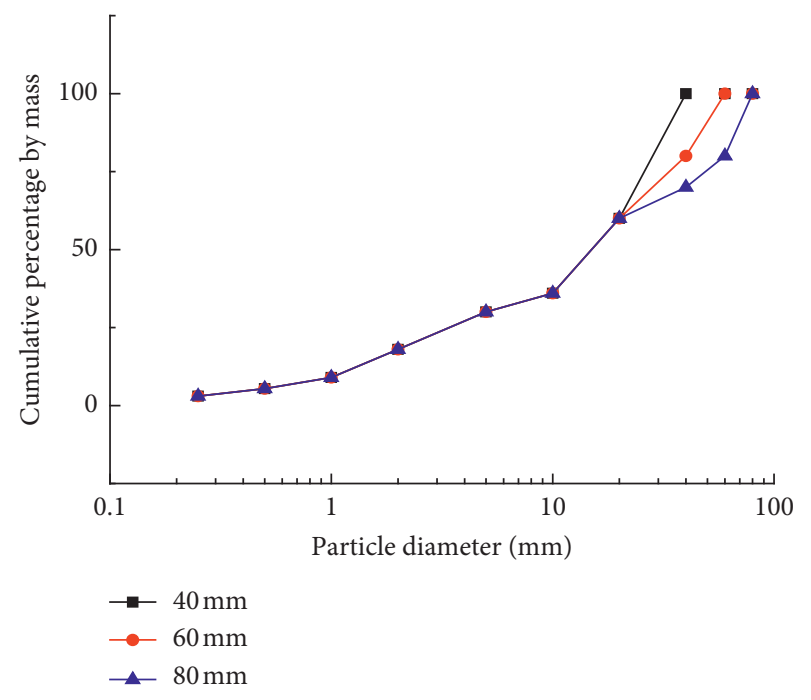

FIgURE 3: Grading curves of samples with different contents of coarse particles.

and oil pump are closed. The load output and pressure lift knobs are opened, and the vertical Jack begins to descend slowly. And then, the load output knob is closed and the vertical precontact is completed, when the vertical jack contacts the power column visually or the vertical load shown on the computer is positive.

(3) Horizontal Precontact. The horizontal cylinder is placed in the loading position, and then, the strain-type output knob is opened. The shear speed is adjusted to maximum, and the oil pump is opened. At this time, the upper shear box is still and the lower shear box is loaded horizontally. When the horizontal load is more than $1 \mathrm{kN}$, the horizontal contact is completed. Then, the oil pump, the horizontal cylinder, and the strain output knob are closed, and the shear speed adjustment knob is reset to zero.

(4) Vertical Loading. Different vertical loads $(200 \mathrm{kPa}$, $400 \mathrm{kPa}, 600 \mathrm{kPa}$, and $800 \mathrm{kPa}$ ) are applied to the samples according to the test plan design. First data acquisition software is open, and the automatic test is clicked to start. Then, "vertical load" is clicked, as shown in Figure 4. Finally, the vertical cylinder is unloaded by the control system, and the load output and pressure drop knobs are opened until the vertical pressure gauge pointer returns to zero. The vertical cylinder is driven to the loading position, and the pressure lift knob is opened. From the computer, the vertical load increases continuously. Until it reaches the designed vertical load, the loading is finished. The shear does not begin until a predetermined vertical load has been applied and the axial deformation is less than $0.03 \mathrm{~mm} \mathrm{~h}^{-1}$.

(5) Horizontal Shearing. After clicking the start of shearing on the computer and entering the control system, the horizontal cylinder is hit to the loading position. The strain output knob is opened and the adjustment knob of shear speed is adjusted moderately, with a shear speed of about $1.2 \mathrm{~mm} \cdot \mathrm{min}^{-1}$. The oil pump is opened, and the shear is

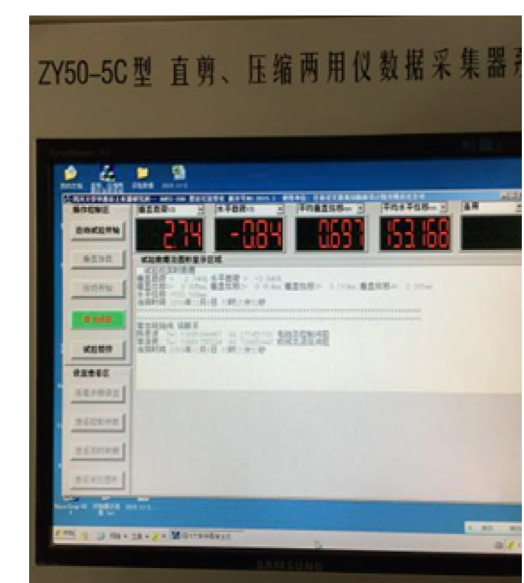

FIgURE 4: Software of the acquisition system.

started. The automatic acquisition system collects the axial displacement, horizontal displacement, vertical load, and horizontal load during the shear process.

2.3.3. Unloading. Unload the horizontal load first, and then, unload the vertical load. After shearing, the horizontal cylinder is changed to the unloading position. The loading output knob is closed, and the vertical fuel supply knob is opened. When there is a gap between the horizontal jack and the reaction beam, unloading is completed horizontally and the oil pump is closed. The loading output knob is opened, and the vertical cylinder is changed to the unloading position. The pressure drop knob is opened, and nitrogen is completely exhausted. And, the vertical fuel supply knob is opened, until the vertical load, displayed by the computer, is zero or unchanged. After the vertical unloading is over, the shear box is cleaned and all the power switches are checked.

2.3.4. Data Processing. In the direct shear test, the shear surface is the plane between the upper and lower shear boxes. During the shear process, the apparatus can acquire the shear displacement and shear stress on the shear plane. With the shear displacement as the transverse coordinate and the shear stress as the longitudinal coordinate, the shear stress vs shear displacement curves under different stress levels can be obtained.

\section{Results and Discussion}

3.1. Shear Stress vs Shear Displacement Curve Characteristics. Figure 5 shows the shear stress vs shear displacement curves of the S-RMs at different maximum particle diameters. The shear process of the S-RMs under different maximum particle diameters can be roughly divided into three stages: strain-hardening stage, strain-softening stage, and secondary hardening stage.

After reaching the peak strength, the shear stress gradually decreases and stabilizes. As the shear displacement increases, the shear stress increases again quickly, and the increased shear stress is greater than the first peak strength. This stage is called the secondary hardening stage. It can be 


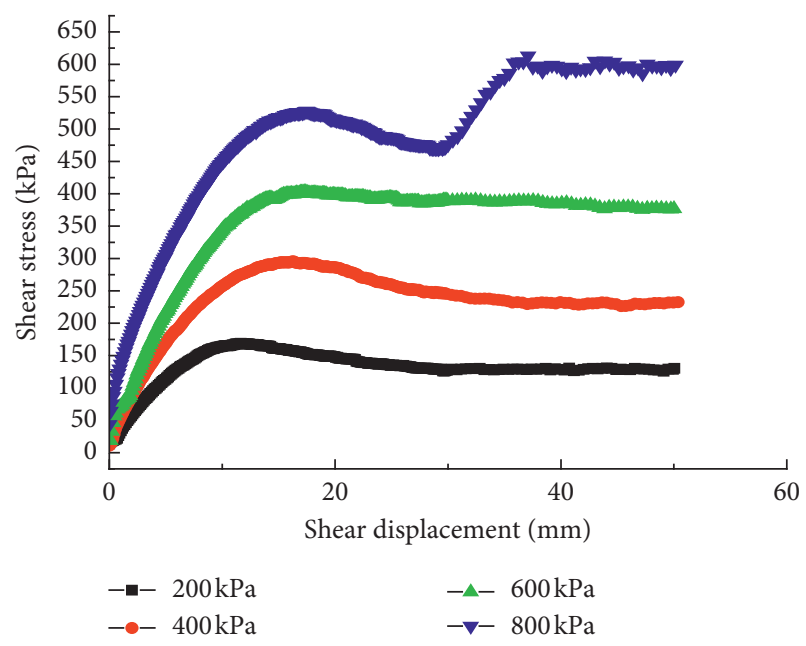

(a)

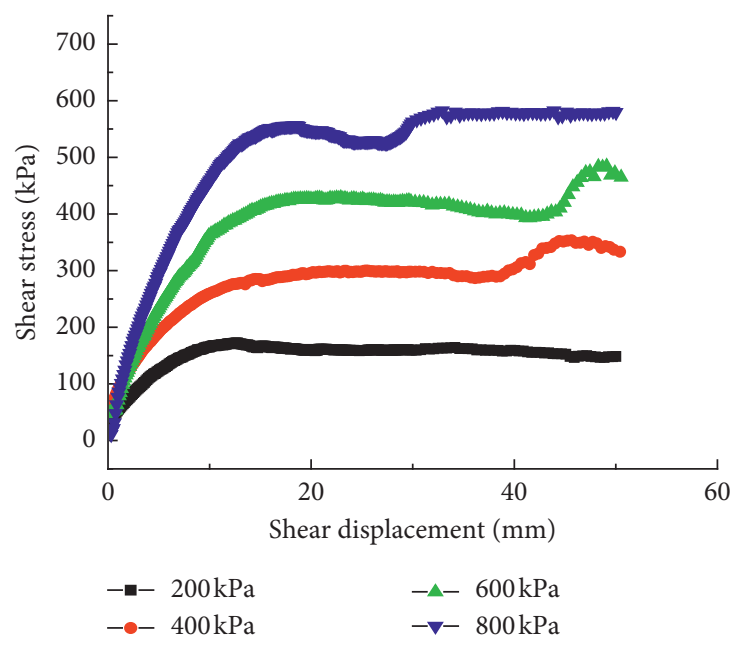

(b)

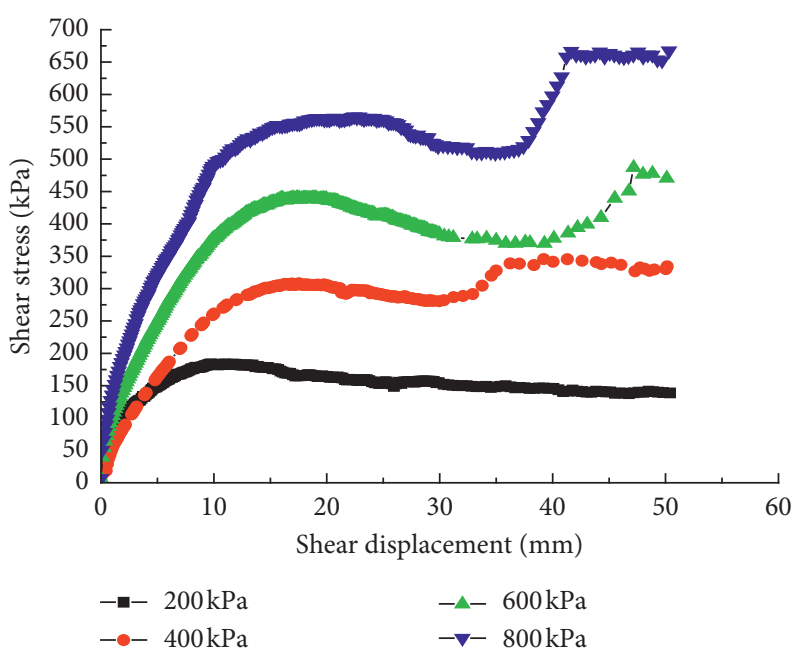

(c)

FiguRE 5: Shear stress vs shear displacement under different maximum particle diameters. (a) $40 \mathrm{~mm}$. (b) $60 \mathrm{~mm}$. (c) $80 \mathrm{~mm}$.

known from Figure 5 that not every group of tests will undergo secondary hardening after strain-softening.

Under low normal stress $(200 \mathrm{kPa})$, no secondary hardening occurs in the S-RMs. Under high normal stress $(800 \mathrm{kPa})$, secondary hardening occurs in the S-RMs. Under moderate normal stress $(400 \mathrm{kPa}$ and $600 \mathrm{kPa})$, the larger the maximum particle diameter of the S-RMs, the more probability that secondary hardening will occur. The secondary hardening is because, that, after the load reaches the shear strength, the particles continue to break and move to form a more stable structure, which causes the strength to rise again. The larger the normal stress and the larger the maximum particle diameter of the filler, the greater the probability that the particles will break and adjust to a tighter structure. Whether secondary hardening occurs mainly depends on the normal stress and the maximum particle diameter of the filler, as shown in Table 2.

3.2. Dilation Characteristic Analysis. Vertical displacement vs horizontal displacement curves under different normal stresses with different maximum particle diameters are
TABle 2: Occurrence of secondary hardening under different conditions.

\begin{tabular}{lcccc}
\hline \multirow{2}{*}{ Maximum particle diameter $(\mathrm{mm})$} & \multicolumn{5}{c}{ Normal stress $(\mathrm{kPa})$} \\
& 200 & 400 & 600 & 800 \\
\hline 40 & 0 & 0 & 0 & 1 \\
60 & 0 & 1 & 1 & 1 \\
80 & 0 & 1 & 1 & 1 \\
\hline
\end{tabular}

Note. "0" means no secondary hardening happening; "1" means secondary hardening happening.

shown in Figure 6. Assume that both the vertical displacement and the horizontal displacement are zero at the beginning of shearing.

From Figure 6, curves can be roughly divided into two types: continuous shearing and beginning of shearing and quick dilation. Under low normal stress, in the beginning of shearing, the particle occlusion is adjusted, and the small particles roll over and slide into the filler pore, resulting in volume reduction and shearing. With the same maximum 


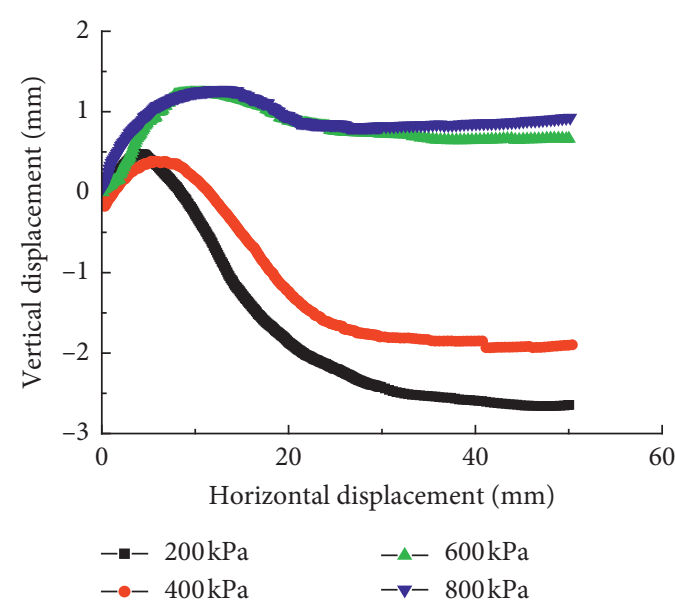

(a)

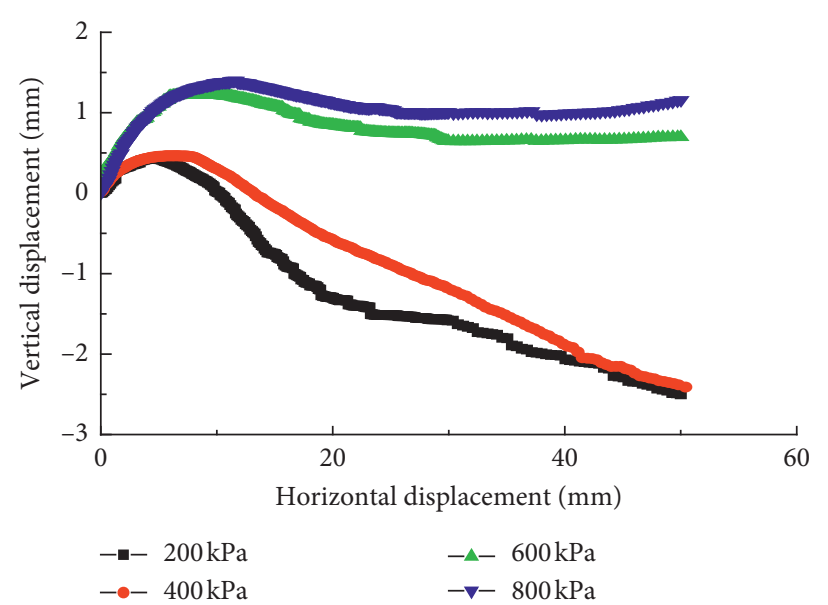

(b)

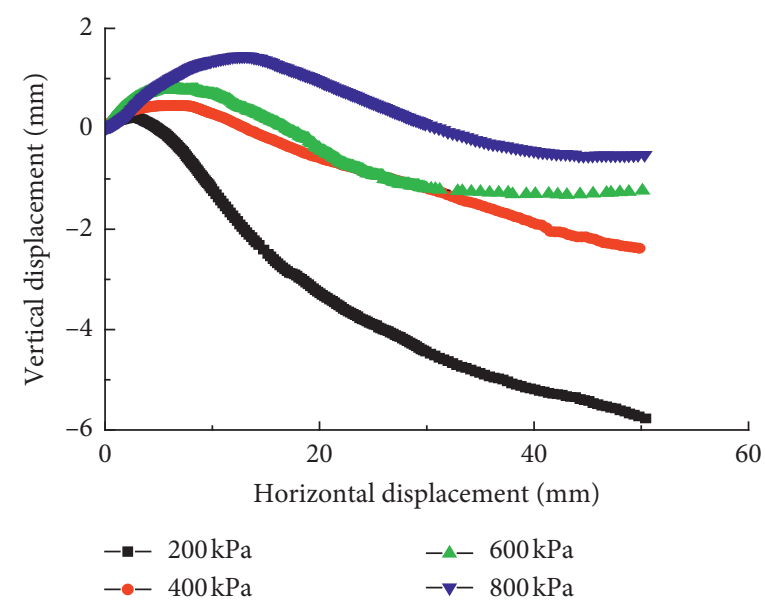

(c)

FIGURE 6: Vertical displacement vs horizontal displacement curves of S-RMs with different maximum particle diameters. (a) 40 mm. (b) $60 \mathrm{~mm}$. (c) $80 \mathrm{~mm}$.

particle diameter, the larger the normal stress, the more obvious the shear shrinkage phenomenon.

When the maximum particle diameter is $40 \mathrm{~mm}$ or $60 \mathrm{~mm}$, the vertical displacement vs horizontal displacement curve under normal stress of $200 \mathrm{kPa}$ and $400 \mathrm{kPa}$ shows shear shrinkage first and then shear dilation (Figures 6(a) and 6(b)). At this time, in addition to roll over and slip, the particle arrangement is accompanied by particle breakage and the broken particles are filled into the filler pore. But to a certain extent, when there is not enough energy, the shear dilation begins to occur. But under normal stress of $600 \mathrm{kPa}$ and $800 \mathrm{kPa}$, the vertical displacement vs horizontal displacement shows continuous shearing (Figures 6(a) and 6(b)). The horizontal displacement vs shear displacement curve of the sample almost coincides with each other, which indicates that the shear dilation under $600 \mathrm{kPa}$ and $800 \mathrm{kPa}$ is more obvious than that under $200 \mathrm{kPa}$ and $400 \mathrm{kPa}$ conditions. At this time, the energy is sufficient and the broken particles are constantly filled into the voids of the sample, so they will continue to shrink.
When the maximum particle diameter is $80 \mathrm{~mm}$, the vertical displacement vs horizontal displacement curve shows shear shrinkage first and then shear dilation (Figure 6(c)). At this time, the particle diameter is larger, and the pore between the RBs can be well filled by the soil. Due to the tight arrangement of the surrounding particles, it is difficult for the particles to move. However, under the action of shear stress, the particles still will roll upwards, resulting in shear dilation. However, under high normal stress, the particles will break up, which will reduce the volume to a certain extent.

3.3. Strength Characteristic Analysis. The shear strength of S-RMs under different maximum particle diameters and normal stresses is shown in Figure 7.

From Figure 7, adding RBs to the filler can increase the shear strength of the filler effectively. With the same maximum particle diameter, the shear strength of S-RMs increases with the increase of normal stress. Under the same normal stress condition, the shear strength of the S-RMs increases with the increase of the maximum particle 


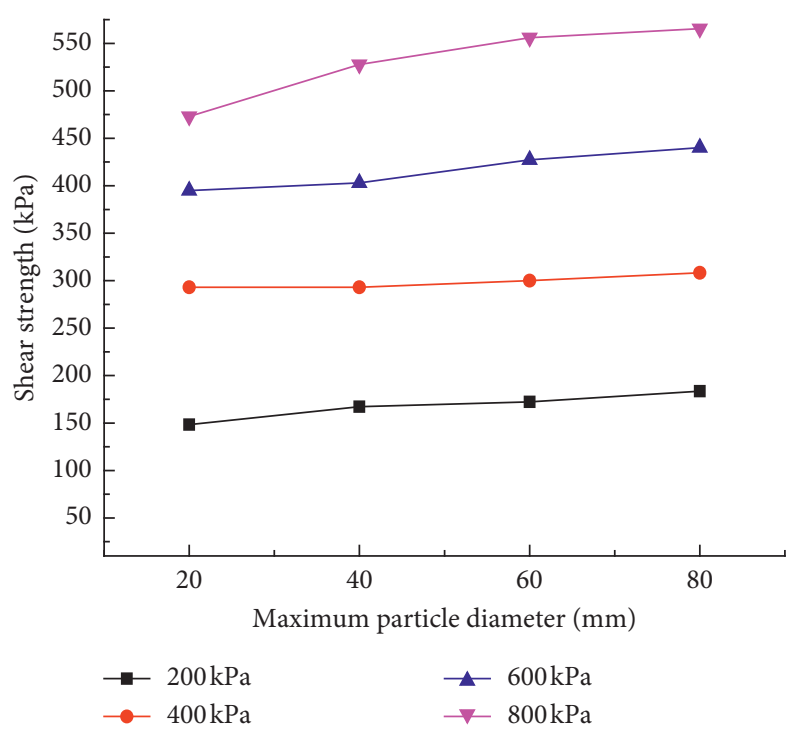

FIgURE 7: Shear strength with different maximum particle diameters.

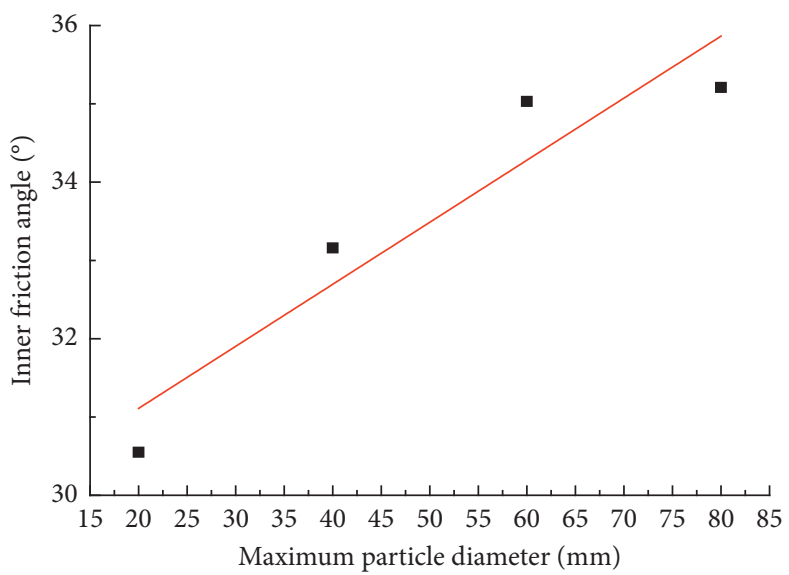

FIgURE 8: Relationship between inner friction angle and maximum particle diameter.

diameter, and the change range of the shear strength is obvious in the range of the maximum particle diameter between $20 \mathrm{~mm}$ and $40 \mathrm{~mm}$, which indicates that adding large-size RBs into the filler can effectively improve the shear strength of the S-RMs. When a certain amount of RBs are added to the filler, a stable structure is formed, and the density increases. And the bite between particles becomes tighter, so the shear strength of the filler increases. With the increase of the maximum particle diameter of the added RBs, the fine particles can also fill the pores better.

According to Mohr-Coulomb shear strength theory, the normal stress and shear stress curves of S-RMs with different maximum particle diameter are fitted linearly by Origin software. The relationship curve between friction angle and maximum particle diameter in S-RMs can be approximated by first-order function, shown in Figure 8 . The fitting function is $\varphi=0.079 d+29.52$, with a correlation coefficient of 0.84 . The relationship curve between cohesion and maximum particle diameter of S-RMs can be approximated by quadratic function, shown in Figure 9 .
The fitting function is $c=77.325-1.0433 d+0.0091 d^{2}$, with a correlation coefficient of 0.87 . At $40 \%$ RBP, the skeleton of the S-RMs has been formed, and its shear strength is mainly reflected on the internal friction angle. With the increase of the maximum particle diameter of the S-RMs, the contact surface among the RBs increases and the shear strength increases, so the internal friction angle of the S-RMs increases with the increase of the maximum particle diameter.

\section{Conclusions}

The S-RMs are special and widespread geomaterial in nature. The mechanical behaviors are influenced by the maximum particle diameter. In this research, laboratory large-scale direct shear tests have been conducted, from which the following conclusions are drawn:

(1) The shear process of the S-RMs at different maximum particle diameters is divided into three stages: strain-hardening, strain-softening, and secondary 


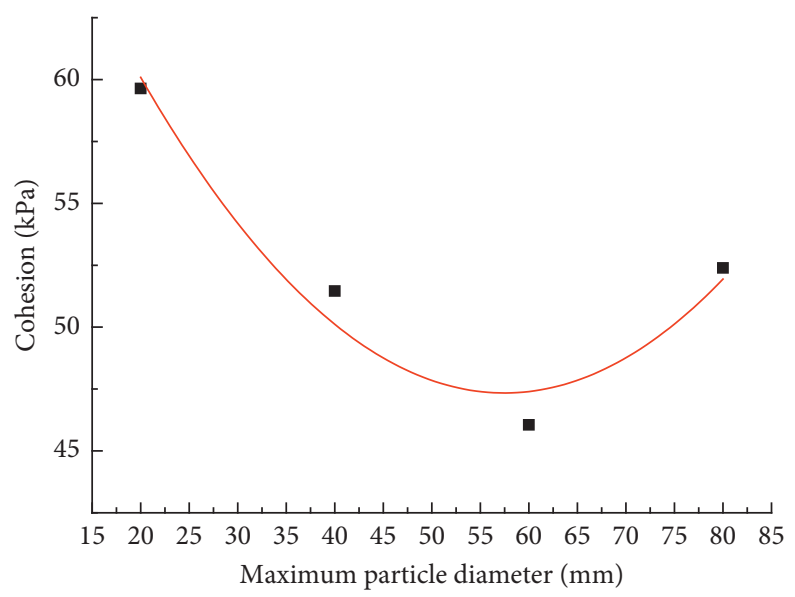

Figure 9: Relationship between cohesion and maximum particle diameter.

hardening. Whether secondary hardening occurs is related to normal stress and maximum particle diameter. And, the larger the maximum particle diameter of the S-RMs or normal stress, the more possible that secondary hardening will occur.

(2) When the RBP is the same, the vertical displacement vs horizontal displacement curve of the S-RMs at different maximum particle diameters can be roughly divided into: continuous shearing and beginning of shearing and then dilation.

(3) When the content of rock blocks is the same, the shear strength of the S-RMs increases with the increase of the maximum particle diameter, the maximum particle diameter is within the range of $20 \mathrm{~mm}-40 \mathrm{~mm}$, and the change range of the shear strength is obvious. The RBs with large particle diameter added to filler can effectively improve the shear strength of the S-RMs.

\section{Data Availability}

The experimental data used to support the findings of this study are included within the article.

\section{Conflicts of Interest}

The authors declare that there are no conflicts of interest regarding the publication of this paper.

\section{Acknowledgments}

This research was supported by the Science and Technology Department of Sichuan Province (Grant no. 18YYJC0044). The work was also carried out under the Subgrade Filled Engineering Research and Development project of the Chengdu East Road Technology Co., Ltd. The authors appreciate àll the institutions and individuals that have provided support for this paper.

\section{References}

[1] Z. Zhang, Q. Sheng, X. Fu, Y. Zhou, J. Huang, and Y. Du, “An approach to predicting the shear strength of soil-rock mixture based on rock block proportion," Bulletin of Engineering Geology and the Environment, vol. 79, no. 5, pp. 2423-2437, 2020.

[2] E. W. Medley, "Systematic characterization of mélange bimrocks and other chaotic soil/rock mixtures," Felsbau Rock and Soil Engineering, vol. 17, no. 3, pp. 152-162, 1999.

[3] E. W. Medley, "Orderly characterization of chaotic franciscan melanges," Engineering Geology, vol. 19, no. 4, pp. 20-32, 2001.

[4] W.-J. Xu, R.-L. Hu, and R.-J. Tan, "Some geomechanical properties of soil-rock mixtures in the hutiao gorge area, China," Géotechnique, vol. 57, no. 3, pp. 255-264, 2007.

[5] W.-J. Xu, Z.-Q. Yue, and R.-L. Hu, "Study on the mesostructure and mesomechanical characteristics of the soil-rock mixture using digital image processing based finite element methodfinite element method," International Journal of Rock Mechanics and Mining Sciences, vol. 45, no. 5, pp. 749-762, 2008.

[6] W. J. Xu, Q. Xu, and R. L. Hu, "Study on the shear strength of soil-rock mixture by large scale direct shear test," Internal Journal of Rock Mechanics Mining Science, vol. 48, no. 8, pp. 1235-1247, 2011.

[7] S. A. Harris and A. 1. Prick, "Conditions of formation of stratified screes, slims river valley, Yukon territory: a possible analogue with some deposits from Belgium," Earth Surface Processes and Landforms, vol. 25, no. 5, pp. 463-481, 2000.

[8] O. Sass, "Determination of the internal structure of alpine talus deposits using different geophysical methods (lechtaler alps, Austria)," Geomorphology, vol. 80, no. 1-2, pp. 45-58, 2006.

[9] N. Coli, P. Berry, D. Boldini, and R. Bruno, “The contribution of geostatistics to the characterisation of some bimrock properties," Engineering Geology, vol. 137-138, pp. 53-63, 2012.

[10] J. M. Buffington, W. E. Dietrich, and J. W. Kirchner, "Friction angle measurements on a naturally formed gravel streambed: implications for critical boundary shear stress," Water Resources Research, vol. 28, no. 2, pp. 411-425, 1992.

[11] L. E. Vallejo and R. Mawby, "Porosity influence on the shear strength of granular material-clay mixtures," Engineering Geology, vol. 58, no. 2, pp. 125-136, 2000.

[12] W. Gao, R. Hu, I. A. Oyediran, Z. Li, and X. Zhang, "Geomechanical characterization of zhangmu soil-rock mixture deposit," Geotechnical and Geological Engineering, vol. 32, no. 5, pp. 1329-1338, 2014. 
[13] Y. Wang, C. H. Li, and Y. Z. Hu, "Use of X-ray computed tomography to investigate the effect of rock blocks on mesostructural changes in soil-rock mixture under triaxial deformation," Construction and Building Materials, vol. 164, pp. 386-399, 2018.

[14] N. Casagli, L. Ermini, and G. Rosati, "Determining grain size distribution of the material composing landslide dams in the northern apennines: sampling and processing methods," Engineering Geology, vol. 69, no. 1-2, pp. 83-97, 2003.

[15] O. Sass and M. Krautblatter, "Debris flow-dominated and rockfall-dominated talus slopes: genetic models derived from GPR measurementsflow-dominated and rockfall-dominated talus slopes: genetic models derived from GPR measurements," Geomorphology, vol. 86, no. 1-2, pp. 176-192, 2007.

[16] D. Cen, D. Huang, and F. Ren, "Shear deformation and strength of the interphase between the soil-rock mixture and the benched bedrock slope surface," Acta Geotechnica, vol. 12, no. 2, pp. 391-413, 2017.

[17] A. Simoni and G. T. Houlsby, "The direct shear strength and dilatancy of sand-gravel mixtures," Geotechnical and Geological Engineering, vol. 24, no. 3, pp. 523-549, 2006.

[18] D.-S. Lee, K.-Y. Kim, G.-D. Oh, and S.-S. Jeong, "Shear characteristics of coarse aggregates sourced from quarries," International Journal of Rock Mechanics and Mining Sciences, vol. 46, no. 1, pp. 210-218, 2009.

[19] M. J. Jiang, H. B. Yan, H. H. Zhu, and S. Utili, "Modeling shear behavior and strain localization in cemented sands by twodimensional distinct element method analyses," Computers and Geotechnics, vol. 38, no. 1, pp. 14-29, 2011.

[20] E. S. Lindquist and R. E. Goodman, "Strength and deformation properties of a physical model melange," in Proceedings of the 1st North American Rock Mechanics Symposium, Balkema Publishers, Rotterdam, Netherlands, pp. 843-850, 1994.

[21] E. W. Medley and E. S. Lindquist, "The engineering significance of the scale-independence of some franciscan melanges in California, USA," in Proceedings of the 35th US Rock Mechanics Symposium, Balkema Publishers, Lake Tahoe, CA, USA, pp. 907-914, 1995. 